\title{
Successful Translation Students' Use of Dictionaries
}

\author{
Nasrin Altuwairesh ${ }^{1}$ \\ ${ }^{1}$ College of Languages \& Translation, King Saud University, Riyadh, Saudi Arabia \\ Correspondence: Nasrin Altuwairesh, College of Languages \& Translation, King Saud University, Riyadh, Saudi \\ Arabia. E-mail: naltuwairesh@ksu.edu.sa
}

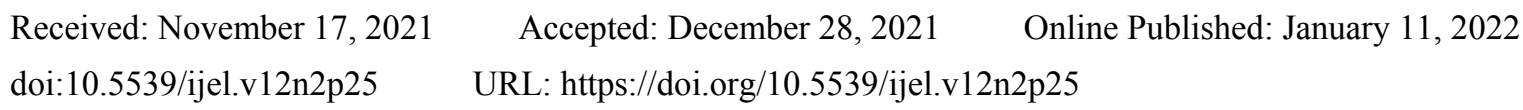

\begin{abstract}
Dictionaries of all types are an indispensable tool for both professional and trainee translators. However, the literature on trainee translators indicates that the skills associated with dictionary use have not been given the required attention. Knowing which dictionaries to use and how to use them efficiently when engaged in the translation process are significant aspects of translation pedagogy. In fact, facilitating the development of effective dictionary use helps develop translation competence in general. Therefore, the present article reports on a qualitative case study of successful translation students' usage of and preferences for various types of dictionaries. The results show that successful trainee translators use dictionaries to locate synonyms or better translations for target words. Successful translation students are also reported to use dictionaries frequently to check spelling. Most respondents reported consulting the dictionary after they finished reading source texts. In line with the global move toward digitalization, the participants reported using electronic dictionaries with significantly greater frequency than paper dictionaries. In most cases, successful translation students' use of paper dictionaries was limited to classroom examinations. The open-ended interview questions also helped to reveal the variety of dictionaries used by this group of trainee translators. Taken together, these findings have utility for translation instructors, particularly regarding the improvement of trainee translators' experiences and the provision of assistance to less successful students.
\end{abstract}

Keywords: dictionary use, e-dictionaries, translation trainees, translation training, translation pedagogy

\section{Introduction}

The success of translation depends on a solid foundation in the basics (Fujii, 2007). Effective dictionary use is undoubtedly a cornerstone in this regard since the usefulness of dictionaries as a tool for translators is an unquestionable matter. The problem lies, however, in the user's efficient and proper use of such tools. Yet research into dictionary use, in general, "does not have a long history" (Nesi, 2014, p. 38).

One problem identified in the literature on trainee translators is that the skills associated with dictionary use have not been given enough attention (Kodura, 2016; Law, 2009). Furthermore, research carried out on dictionary use indicates that not all dictionary users have appropriate skills, which is especially true regarding electronic dictionaries (Mavrommatidou, 2018). Recent efforts have been made to improve dictionaries, but little has been done to discover how to equip dictionary users with better skills when interacting with dictionaries (Lew, 2013a). Moreover, there is a paucity of literature on dictionary users' behaviors and preferences, with the only studies in this area having been conducted to investigate language learners and not translators (Lew \& De Schryver, 2014).

Recently, due to the prevalence of technology, learners around the globe are showing a preference for free electronic resources (Lew \& Szarowska, 2017). In the case of dictionaries, as the status of these resources has experienced drastic changes (e.g., changes in modes of access), so too have the patterns of user behavior shifted (Liang \& Xu, 2018). Therefore, since little has been done to build the profiles of trainee translators regarding their dictionary use and preferences, this paper investigates the dictionary use practices and preferences of a group of successful trainee translators.

\section{Literature Review}

\subsection{Translation Competence}

A major skill for any professional translator is the skill of dictionary use. In particular, efficient dictionary use is a critical skill that every trainee translator must acquire. Several models that account for translation competence 
have been identified in the literature, one of which was proposed by the PACTE research group, where PACTE is an acronym for Process in the Acquisition of Translation Competence and Evaluation. According to this organization, translation competence is defined as the "the underlying knowledge system needed to translate" (PACTE Group, 2005, p. 610).

The consensus among researchers in the field is that translation competence consists of a number of interrelated sub-competences, but the clear definition of these sub-competences is still a debatable matter (Göpferich, 2009). However, the PACTE research group states that translation competence is a form of expert knowledge that mainly consists of procedural rather than declarative knowledge, where procedural knowledge draws the line between expert and novice translators. According to the PACTE research group, translation competence is made up of five interrelated sub-competences: namely, the bilingual, extra-linguistic, knowledge about translation, strategic, and instrumental sub-competences.

The instrumental sub-competence is defined as "procedural knowledge related to the use of documentation sources and any information and communication technologies applied to translation: dictionaries of all kinds, encyclopedias, grammars, style books, parallel texts, electronic corpora, searchers, etc." (PACTE, 2003, p. 59). Knowledge related to the use of documentation sources and information technologies that are applied to translation falls under the instrumental sub-competence. Hence, it is under this component of translation competence where the skill of dictionary use comes into play.

\subsection{Language Dictionaries}

The literature on language dictionaries offers several typologies for language dictionaries, many of which are in use nowadays. However, with the advent of new ways of presenting information on word use and meaning, the distinctions that have been traditionally drawn between the various groups of reference work "are becoming increasingly blurred" (Nesi, 2000, p. 839). Finding a typology for reference texts such as dictionaries is a rather complex matter, yet the basic options available for users include monolingual and bilingual dictionaries, on the one hand, and hard copy along with electronic dictionaries, on the other hand (Nesi, 2013). This entails that language dictionaries can be simply divided into two broad groups based on either their language basis or their design (Tulgar, 2017). The former group includes monolingual dictionaries as opposed to bilingual dictionaries, while the latter includes print dictionaries (found in hard copies) and electronic dictionaries (further divided into online and offline dictionaries). This basic and rather straightforward division will be adopted in the present paper.

The term that is broadly used for digital-media dictionaries is "electronic dictionaries", which is often abbreviated as e-dictionaries (Lew \& De Schryver, 2014). Electronic dictionaries are defined as "any reference material stored in electronic form that gives information about the spelling, meaning, or use of words" (Nesi, 2000 , p. 839). The retrieval system of electronic dictionaries, rather than the information found in them, is what makes using them a revolutionary experience when compared to consulting paper dictionaries (Nesi, 2000). The advent of electronic dictionaries has profoundly changed dictionaries and lexicography in general (L'homme \& Cormier, 2014).

Electronic dictionaries have many advantages over paper dictionaries, including ease of access, convenience and speed of word searches (due to the absence of alphabetical order), and the availability of pronunciation information (Nesi, 2000). Further, electronic dictionaries offer varied selections of up-to-date vocabulary items and language expressions that can be used in real-world situations, as well as technical jargon (Fujii, 2007). Moreover, one advantage often mentioned when researching electronic dictionaries is that there is no limit to the amount of data that can be added to them (L'homme \& Cormier, 2014). This can be taken, however, as a disadvantage on the user end because users face the risk of being overwhelmed with the amount of data provided by electronic dictionaries; as a result, it may be challenging to locate the required information easily and accurately. Nevertheless, all of the improvements found in electronic dictionaries make them seem more of a "simulated language expert" as opposed to the "less intelligent and bulky wordlist of yesterday" (Lew \& De Schryver, 2014, p. 351).

Despite the advantages of electronic dictionaries over paper dictionaries, concerns remain as to whether they do, as a matter of fact, support learning and improve instant understanding of the information they provide (L'homme \& Cormier, 2014). In fact, studies have found that information retrieved from print dictionaries is retained much more effectively than information from electronic dictionaries, which is attributable to the greater effort involved in using a paper dictionary (L'homme \& Cormier, 2014).

When comparing paper dictionary reference skills to electronic ones, the most radical changes regarding paper dictionary reference skills relate to looking up and accessing lexicographic information (Lew, 2013a). Language 
learners today seem to strongly prefer free online dictionaries over other dictionary types (Lew \& Szarowska, 2017). As for the skills relating to the actual content of these two broad groups of dictionaries, user experiences greatly overlap between paper and electronic dictionaries (Lew, 2013a). However, the problem with free electronic dictionaries is that their quality often varies greatly, which poses a problem for average language learners who lack the ability to assess the quality of these sources competently (Lew \& Szarowska, 2017).

Lew (2013a) further explained that the knowledge available regarding the skills needed for effective paper dictionary use is far from complete, which is due to the absence of a sound empirical grounding. Although electronic dictionaries have become very popular among language learners and users nowadays, few attempts have been made to evaluate them systematically (Lew \& Szarowska, 2017). However, Nesi (2014) identified the following five recurring themes in the literature on dictionary use: language learners' preferences and attitudes towards dictionary use, the influence of dictionaries on language learners' text comprehension, the influence of dictionaries on language learners' text production, the role of dictionaries in facilitating English language learning, and the dictionary consultation behavior of learners. The research to date on dictionary use has aimed ultimately at helping dictionary users to consult dictionaries more efficiently, despite the fact that progress in this respect has been rather scarce (Nesi, 2013). Moreover, the skill of dictionary use is often studied in research on foreign language acquisition, and studies that aim to uncover students' use and perceptions of dictionaries have tended to focus on foreign language learners (Kodura, 2016). Beyond the group of foreign language learners, little attention has been paid toward other groups of dictionary users.

\subsection{Studies on Dictionary Use}

Tulgar (2017) conducted a qualitative study to identify Turkish EFL learners' views regarding their usage of and preferences for different dictionary types. The researcher conducted classroom observations for a sample of 71 undergraduate students enrolled in a Turkish-English translation course over a one-semester period. The types of dictionaries that the students preferred to use were noted, as well as how often they used dictionaries and the specific information they were seeking to retrieve.

In the next phase of their research, Tulgar (2017) asked 12 students from the same sample, whom she noticed would consult the dictionary frequently and utilized both print and online dictionaries, to participate in semi-structured interviews. The aim was again to uncover their perceptions about dictionary use, along with their preferences. The results revealed that most participants used online dictionaries due to their convenience. The study further confirmed that the participants do in fact appreciate the advantages of paper dictionaries and they believe that they are more informative than online ones. They also believe that paper dictionaries help them learn new words while consulting the dictionary, which is something that is not necessarily achieved when using online dictionaries (i.e., as they feature only the searched vocabulary items).

As mentioned previously, most studies on dictionary use to date have focused on language learners (Chen, 2010; Hamouda, 2013; Wolter, 2015). Other studies have investigated EFL learners' use of dictionaries when completing translation tasks (Liang \& Xu, 2018; Tulgar, 2017). One exception to this is the study carried out by Sabbah and Alsalem (2018), which attempted to investigate translation students' knowledge, patterns of use, and attitudes toward different kinds of online dictionaries as well as terminology databases. The main aim behind this study was to reveal the extent to which the participants were aware of the existence of online resources that can be of help to translation trainees.

Sabbah and Alsalem (2018) reported that most participants used dictionary apps and online dictionaries rather than traditional paper dictionaries. Furthermore, most participants reported using both monolingual and bilingual dictionaries. The top source, according to the study's participants, was Almaany, which is a free, electronic, and multilingual dictionary; after this, the second-leading source for the participants was the Cambridge Dictionary. Other online dictionaries the students reported a preference for included the Oxford Dictionary, Reverso, Glosbe, The Free Dictionary, Alqamoos, and Word Reference. When asked about why they would consult the dictionary, participants in Sabbah and Alsalem's (2018) study mentioned the following purposes: checking meaning, translating from English to Arabic, checking synonyms, and, as mentioned by a few students, checking spelling and looking for examples of word usage.

Another study that investigated the use of dictionaries by students majoring in translation was performed by Kodura (2016). The aim of this study was to verify the assumption relating to the general shift regarding dictionary use and other aids among translation students. The study also aimed at gaining insight into the tools used by these students. The results confirmed the generally observed shift toward online resources and the largescale departure from the use of traditional paper dictionaries. Among the reasons given by the participants for their preference of online dictionaries, the students mentioned that they are faster, more cost-effective, and 
more convenient than paper dictionaries. The study also revealed that these students do not use portable electronic devices, nor do they use electronic dictionaries on CD-ROMs. The study reached the conclusion that there is a need for activities that focus on the use of various tools and resources available for translators, which should ideally be implemented in translation courses. The authors suggested that there should also be a special emphasis on evaluating these sources in terms of both usefulness and reliability.

\subsection{Summary}

Based on this review of literature available on dictionary use, and to the best of my knowledge, no studies to date have been conducted on the usage and preferences of successful Saudi trainee translators for different types of dictionaries. However, uncovering how successful translation trainees use dictionaries is expected to have a beneficial impact in informing translation pedagogy. In light of this, translation trainers can assist less successful translation trainees on the journey to becoming successful translators. Facilitating the development of effective dictionary use helps develop translation competence in general. Being efficient at using different types of dictionaries during the translation process is, in fact, at the heart of translation pedagogy (Roberts, 1992). Therefore, this paper aims to investigate successful translation trainees' use of dictionaries with the objective of informing translation pedagogy.

\section{Methods}

This paper reports on the second part of a mixed-methods study that utilized both questionnaires and interviews to investigate undergraduate translation students' uses of and preferences for different types of dictionaries. Nesi (2014) stated that research into dictionary use is usually characterized by studies that are small-scale, rather than large-scale ones. Also, the literature on dictionary use further points to the lack of studies that examine learners' dictionary preferences from a qualitative perspective (Tulgar, 2017). Thus, this article reports on a small-scale, qualitative case study of successful translation trainees' dictionary usage and preferences.

\subsection{Research Question}

This qualitative study aimed to answer the following research question: namely, what are the uses and preferences of successful translation trainees for different types of dictionaries?

\subsection{Participants}

The first part of the study was based on a multi-item questionnaire as the main data collection method. The questionnaire was sent to the participants as an online link. A group of 95 students completed the questionnaire. Participants who were involved in the first phase of the study (i.e., the quantitative phase) were recruited using convenience sampling as they were enrolled in a course taught by the researcher herself. The study's participants were all female undergraduate students at the College of Languages and Translation at King Saud University in Riyadh. Their age range was 21-23 years old and they were all completing a level eight course in translation during the academic year 2017-2018. At the time of the study, the participants had already completed up to seven translation courses, both written and oral (Altuwairesh, 2021).

In the second part of the study, which this article reports on, seven successful students from the same sample that completed the previously mentioned questionnaire were invited to participate in answering several open-ended interview questions. These seven students were classified as successful because, according to their GPAs, they were at the top of their cohort. The open-ended interview questions sought to find out when in the translation process the participants consulted the dictionary and what information they seek to retrieve. The interview questions also aimed to reveal the participants' views on the different types of dictionaries (i.e., paper vs. electronic dictionaries) and the dictionaries they frequently use when undertaking translation tasks.

\subsection{Instruments}

Roberts (1992) identified the following four main problems that translation trainees face when using dictionaries: what information to look up in the dictionary, where to find lexical information, how to make sense of lexical information, and when - as well as how - in the translation process to consult dictionaries. Based on these four major problems, I devised a set of interview questions to uncover information relating to the type of information the participants look up, where they locate such information, and at what point in the translation process they consult the dictionary. The problem of making sense of lexical information is beyond the scope of this study, and thus was not tackled in the interview questions. Since these areas were identified by Roberts (1992) as the major areas that might cause problems to translation trainees when using dictionaries, eliciting the responses of successful translation trainees will help gain insight into how this group of trainees deals with such problems. In turn, trainers can transfer such knowledge to less successful translation trainees. 
As previously stated, this study aimed to answer the following research question: what are the uses and preferences of successful translation trainees for different types of dictionaries? The first part of the question helps to illuminate the stage at which successful translation trainees consult dictionaries during a translation task. It also helps in knowing the specific pieces of information these participants attempt to retrieve when using dictionaries. Additionally, the second part of this research question facilitates revealing the translation trainees' preferences for certain types of dictionaries. It will further show what they think of electronic dictionaries, on the one hand, and paper dictionaries, on the other, as well as the dictionaries they often consult from each group.

\section{Results}

The interview questions helped to gain insight into the uses and preferences of the participants of this study, namely seven successful translation trainees. Based on the research question, this results section is divided into two major sections: one focusing on the participants' uses of dictionaries and another examining their preferences in terms of the different types of dictionaries available for use.

\subsection{Participants' Dictionary Usage}

The first thing the participants were asked about was the point in the translation process at which they consult the dictionary when undertaking a translation task. Most of the participants reported that they consulted the dictionary after reading the text for the first time, or after translating the text, as one participant said:

After reading the entire text and making sure I understand it, I underline the words that needed to be looked up in the dictionary. Then I begin translating each sentence and whenever it has an underlined word, I look it up.

Another participant said:

After reading the text and underlining the words that I need to look up and before starting to translate.

One participant said:

Usually, when I read a text for the first time, I tend to analyze it and underline the words that I do not know. If I have enough time, I try to figure out their meanings by the context first and then check a dictionary.

Others stated that they consult the dictionary while translating, especially when sitting an examination. For example, one student reported:

While translating — specifically when I encounter a word for which I'm unfamiliar with its meaning.

Another student said:

While I'm translating. I directly check for the correct word to use because if I leave it for later, I might forget or not have time to revise.

In the case of the last participant, they are clearly referring to exams, which is reflected in the participant's reference to the situation of running out of time.

An important and effective dictionary skill is knowing when not to use the dictionary. Reading the source text as a whole is an important stage in the translation process that occurs prior to consulting the dictionary. Based on the participants' responses above, the findings of this study are thus in line with the common advice given to translation trainees. According to Roberts (1992), this advice suggests withholding the use of dictionaries when attempting to analyze the text, and using it only when the text has been read thoroughly, as well as after having tried to figure out the meanings of unfamiliar words based on the context.

When asked about the types of words they often look up in a dictionary, the successful trainee translators reported consulting the dictionary to find synonyms or better translations of the words they are translating, along with words they are unfamiliar with. One participant, for example, said:

I normally consult the dictionary whenever I am faced with specialized terms or whenever I need to use more expressive terms than general ones.

Another participant said:

I usually look for synonyms that better express the meaning I already know

One participant also stated that she looks up many kinds of words, one of which is:

Words that I know how to translate but for which I want to find a better translation.

The participants' responses also indicated that they often use the dictionary to check spelling. For example, one participant stated "I sometimes check for spelling", and another reported on their use of dictionaries as involving 
looking for "words that I need to check on their spelling".

The pieces of information the participants of this study reported looking for when consulting the dictionary are similar to those mentioned by the participants in Sabbah and Alsalem (2018). This finding, in particular, signifies a major difference between successful translation trainees and other trainees. Based on the results of the first part of this study, the questionnaire results indicated that the participants use the dictionary mainly to check for meaning. On the other hand, the results of this part of the study show how this group of trainees go beyond checking meaning to looking for synonyms, better translations, more expressive terms, and others, which are all indications of their attempts to improve their output (i.e., the translated text).

\subsection{Participants' Dictionary Preferences}

When deciding on consulting a certain dictionary, the students were found to make use of the prior knowledge about different dictionaries, and they also sought to make informed decisions based mainly on the type of information they were after. When the participants were asked about the types of dictionaries they frequently used, they reported on using electronic dictionaries more often than paper ones. For example, the responses of several participants are shown below.

When translating at home, I rely on online dictionaries. During exams and classwork, however, I use paper dictionaries.

I've been recently using electronic dictionaries more than paper ones.

I use paper dictionaries only in exams, while most of the time I use electronic ones.

I use electronic dictionaries more often than paper ones.

Mostly English general dictionaries (online).

With the digital revolution, a common finding that has been supported by the results of the current study is dictionary users' shift to electronic dictionaries (Lew, 2013b). This shift has been confirmed by the results of many studies in the field, including Kodura (2016), Sabbah and Alsalem (2018), and Tulgar (2017).

Additionally, when the participants were asked about the electronic dictionaries they regularly use, all mentioned using Almaany, which is a comprehensive, multilingual dictionary that provides translation between Arabic and several other languages. This is similar to the finding reached by Sabbah and Alsalem (2018), where Almaany was listed as the number one source used by their respondents. The participants of the current study further reported using some monolingual online dictionaries, as well as dictionary apps, including:

Almaany; Dictionary by Merriam-Webster; Oxford English Dictionary

Almaany (website), and Arabic Dictionary (App.).

Oxford Dictionaries, Reverso Context, and Almaany.

Dict Box App.; Almaany; Merriam-Webster; Urban Dictionary App.

Several of the participants stated that they simply Google the word they are looking for. For example, one participant reported the following:

[I use] Almaany, Cambridge, and Oxford's collocation dictionary. But most of the time when I look for a word, I just Google it.

Similarly, another participant stated:

[I use] google.com (Googling the word).

Surprisingly, two of the participants reported using Google Translate. Noteworthily, one of the participants placed Google Translate at the top of her list:

Arranged according to the most frequently used ones: Google translate, Cambridge dictionary (I like it because it provides the British and American contexts and proverbs), google.com (Googling the word), and Merriam-Webster.

This finding is quite surprising given that the sample focuses exclusively on successful translation trainees. This is because translation trainees are often advised by their instructors to avoid the use of Google Translate due to the low-quality translations it produces.

The students were also asked about when they usually consult electronic dictionaries. Several of the participants reported that they restricted their use of electronic dictionaries to when practicing at home. Others elaborated and provided more detail on this point, stating: 
I tend to use an electronic dictionary whenever I am reading an online book or article, using Twitter, or watching videos. I also use it rarely whenever I have a translation project or homework.

Another student explained her approach to consulting electronic dictionaries as follows:

When translating texts other than the ones in exams, I prefer to figure out meanings by myself from the context because I have time to do so. Also, for me, checking an electronic dictionary would be the last step before revising the whole text, just to make sure that I got the meanings right.

The students were further asked about the problems they may face when using electronic dictionaries. The main problem that was mentioned related to Internet connection, as shown by the following responses:

The only problem is that it requires an Internet connection.

Using an electronic dictionary, I always face multiple problems, including Internet connection, pop-ups and ads, and not having everything in one place.

These types of dictionaries can't be used without an Internet connection, and it is sometimes difficult to use them in a location where the connection is poor.

On the other hand, one participant mentioned that she rarely faces any problems with electronic dictionaries, and that the problem of having to be connected to the Internet is solved with dictionary apps that work offline (e.g., Dict Box). Another participant explained that this type of dictionary is associated with fewer problems compared to paper dictionaries:

There are fewer problems for sure [with electronic dictionaries] compared to paper dictionaries. I don't think I have faced any problems using electronic dictionaries before, but maybe they're hard to use for people who aren't familiar with technology.

The students further complained about the number of ads and pop-ups encountered when using electronic dictionaries, as well as the problem of not finding all relevant information in one place:

Electronic dictionaries can sometimes be a mess. You usually have to open a couple of tabs on your browser and go through multiple websites to get one word.

Another participant described annoyance arising from similar problems:

I do not believe that there are problems regarding electronic dictionaries but because most of these dictionaries are free, there are too many advertisements, which is annoying.

Additionally, one participant mentioned that the problem she faces when using electronic dictionaries was:

Usually, I have to use more than one dictionary to fully understand the term.

One of the participants also explained that their perceived disadvantage of using electronic dictionaries was the problem of not retaining information about words for long. This finding, noteworthily, corroborates the results of Koyama (2015), which indicated that despite the reduction in dictionary users' look-up times, using electronic dictionaries has no guarantee regarding the degree of retention of the words looked up compared to paper dictionaries.

The students were also asked about when they used paper dictionaries, revealing that there was a consensus that the use of paper dictionaries was restricted to exams. This result is another indication of the participants' heavy reliance on electronic dictionaries. Some of them mentioned using paper dictionaries when doing their homework:

I use them $98 \%$ of the time for doing homework and exams.

During mid-terms and final exams only. I never use it outside of the university.

I only use paper dictionaries in exams when I encounter new words or when I want to find synonyms of certain words.

I use paper dictionaries the most during exams or whenever I have homework. I rarely use them at home and only if the words I'm looking for are not found online or the online dictionaries don't provide much meaning.

When asked about the paper dictionaries they used most frequently, all of the participants agreed on using Almawrid, which is a two-way, bilingual dictionary. They also mentioned using monolingual dictionaries, including the Oxford Advanced Learner's Dictionary and a number of specialized bilingual dictionaries. For example, the participants mentioned: 
Most of the time, I find myself using the Almawrid Arabic-English Dictionary and the Oxford Advanced Learner's Dictionary.

I use the Oxford Advanced Learner's Dictionary to look up words whenever I am reading a book in English. I use Almawrid and Almurshid when I need a bilingual dictionary.

Almawrid (English-Arabic), Almurshid (Arabic-English), and the Oxford Concise Thesaurus (English).

Oxford Advanced Learner's Dictionary and Almawrid (not so often and I use it when practicing).

I use Almawrid most of the time. Over the past semester, I started using the Dictionary of Islamic Terms and Hitti's Medical Dictionary for my Islamic and medical translation courses.

The participants were also asked about the problems they encounter when using paper dictionaries. They mentioned a number of problems, including their perception that paper dictionaries were time-consuming to use, heavy to carry around, not up-to-date, not comprehensive, and lacking in sound to assist with pronunciation:

It takes time to look up words and sometimes I don't even find them anywhere.

When comparing [paper dictionaries] to electronic ones, I find that paper dictionaries are time-consuming and they do not offer as much information as electronic ones do.

Two main problems: one, it takes longer to look up a word in a paper dictionary compared to an electronic one; two, paper dictionaries (or at least the ones I use) don't provide many examples of a word in context. And if they do, they usually display the word in a fragment, not a sentence. Reading a word in different sentences is very important to me to actually understand its meaning.

There are a couple of problems that I typically face whenever I use a paper dictionary. The first is that they don't normally offer examples. They are also time-consuming; it generally takes a lot of time until you find the right word. Sometimes, they can be heavy to carry around.

They are heavy and inconvenient to transport, mostly written in small font sizes, and can take too long to simply look for a word. They also lack certain words, either because the words are newly invented or simply insignificant. And some paper dictionaries do not have additional information besides a word's direct translation.

A major step in dictionary consultation relates to selecting an appropriate dictionary. The students' responses to the interview questions revealed their awareness of a good selection of dictionaries, both paper and electronic ones. However, similar to the participants in Kodura (2016), the students in this study did not report using any portable electronic dictionary devices, nor any CD-ROMs. Their responses did, in fact, demonstrate their heavy dependence on online dictionaries and mobile apps.

\section{Discussion and Conclusion}

The results of this study indicate that the participants clearly favor the use of electronic dictionaries over paper ones. However, their responses illustrate that they might at times integrate the use of both. This finding is similar to the result Tulgar (2017) reported after surveying a group of students enrolled in a Turkish-English translation course. The classroom observation data collected by Tulgar demonstrated that when searching for meaning, the participants used online dictionaries more often than paper ones. Significantly, the interview data showed that Tulgar's participants had a general tendency to integrate both online and paper dictionaries, which is similar to the participants of the present study.

One of the participants in the current study stated that she tended to use paper dictionaries "only if the words I'm looking for are not found online or the online dictionaries don't provide much meaning". This is similar to the reasons given by the participants in the study carried out by Tulgar (2017), where one of them stated the following: "On the other hand, print dictionaries, as far as I am concerned, contain much more information". Another participant in Tulgar's study reported that "sometimes I cannot be sure whether the meaning or usage in an online dictionary is really true. Then, I need to check the meaning again in a print dictionary because it is much more detailed and reliable than its online counterpart" (p. 54).

Lew (2013a) stated that with the rapid move to electronic dictionaries, paper dictionaries are already becoming "yesterday's news" (p. 83). However, this is not the case in the context of the present study, as the successful translation trainees were, in fact, found to use paper dictionaries, especially when completing homework and sitting examinations. Both paper and electronic dictionaries represent valuable language tools that meet a spectrum of learners' needs and requirements (Mavrommatidou, 2018). One characteristic of electronic dictionaries that has played a critical role in dictionary users' shift to these digital resources lies in their 
portability and mobility. These were mentioned by the participants in this study in response to the question about the advantages of using electronic dictionaries. This feature, in particular, gave learners the chance to learn on the go, with no restrictions in terms of time or place (Levy \& Steel, 2014).

When comparing paper dictionaries to the digital medium, it is important to recognize that the use of the latter calls for the activation of knowledge and skills that are of a higher level and, therefore, should be transferred to students via classroom instruction (Mavrommatidou, 2018). The literature demonstrates that many dictionary users seem to lack the required skills, particularly when attempting to use digital dictionaries (Mavrommatidou, 2018). These skills, in fact, do not come naturally to learners (Law, 2009). This point is reflected in the participants' responses to the question regarding the problems they face when using electronic dictionaries, particularly when they referred to the process of consulting an electronic dictionary as being "quite a mess" and "not having everything in one place". Lew (2013b) explained that "the electronic medium accommodates a greater variety of types of structures, and this can present a serious challenge to users - even those experienced in using paper dictionaries" (p. 19). The problem is that the literature on electronic dictionary users has little to say about the behaviors and preferences of this group of users, "while there are no valid and reliable tools for recording users' psychometric characteristics when selecting and using dictionaries" (Gavriilidou \& Mavrommatidou, 2016, p. 168). In view of this, guiding dictionary users on the effective use of the digital medium can be quite challenging.

Most research available to date has focused on the ways to improve dictionaries, with little attention dedicated to educating the users of these dictionaries (Lew, 2013b). Empirical evidence exists for the teachability of effective dictionary skills, yet the question posed by results of studies in the field is who can teach these skills, particularly e-dictionary skills, and how, especially given the fact that educators seem to struggle to keep up with the pace of changes occurring to these tools (Lew, 2013a). Investigating how successful translation trainees use electronic dictionaries will undoubtedly help in this regard.

Trainers who find themselves unable to keep abreast with new advances can potentially pair successful students with less successful peers in an attempt to make use of peer support. Dictionary skills are often not taught in a systematic way in educational contexts, and even if some teaching takes place, it seldom includes any training on the selection and criticism of dictionaries (Nesi, 2013). Many professional translators acquire competence in terms of dictionary use through experience, which is because language courses rarely allow for training on the effective use of dictionaries. However, by uncovering the uses and preferences of successful translation trainees and sharing this information with their less successful peers, translation trainers can help underachieving students on the journey to becoming effective and more successful translators.

The initial aim of this study was to compare the use of dictionaries among successful students and less successful students. The same invitation was sent to a sample of participants from both groups and, surprisingly, all participants from the former group (i.e., the successful participants) responded and agreed to take part in this study, whereas all participants from the less successful group never responded to my invitation. This, in fact, raised a few questions in my mind as a researcher. Was their decision to ignore the invitation attributable to their awareness of limitations in their ability to use dictionaries? Did these students lack confidence about how to utilize electronic dictionaries? One important point is that it is quite unsafe to generalize from the results about how individuals use dictionaries, particularly given that "dictionary users, uses, and contexts of use can all vary enormously" (Nesi, 2013).

Dictionaries have been viewed as an authoritative reference for a long time (Lew \& De Schryver, 2014), but the popularity of electronic dictionaries in recent years has undoubtedly changed this position. In fact, "the digital revolution has not spared the dictionary and its centuries of almost sacred authority over users" (L'homme \& Cormier, 2014, p. 336). To conclude, studies conducted with a focus on dictionary use have, in fact, grown in popularity over the last few decades. The advent of technology as well as the popularity of electronic dictionaries among dictionary users calls for more research into user behaviors and preferences. Studies on how electronic dictionary users make sense of the lexical information they find in these digital repositories highlight one noteworthy area of study. Another area worth investigating is how we can bridge the gap between this tech-savvy generation, on the one hand, and the older generation, on the other hand, who may not be as familiar with technology, along with its ins and outs.

\section{References}

Chen, Y. (2010). Dictionary use and EFL learning. A contrastive study of pocket electronic dictionaries and paper dictionaries. International Journal of Lexicography, 23(3), 275-306. https://doi.org/10.1093/ijl/ecq013

Fujii, Y. (2007). Making the most of search engines for Japanese to English translation: Benefits and challenges. 
The Asian EFL Journal Professional Teaching Articles, 23, 1-36.

Gavriilidou, Z., \& Mavrommatidou, S. (2016). Construction of a Tool for the Identification of Electronic Dictionary Users'Skills: Test Specification and Content Validity (pp. 168-178). XVII Euralex International Congress. Retrieved from https://euralex.org/wp-content/themes/euralex/proceedings/Euralex2016/euralex_2016_014_p168.pdf

Göpferich, S. (2009). Towards a model of translation competence and its acquisition: The longitudinal study Trans Comp. In S. Göpferich, A. L. Jakobsen \& I. M. Mees (Eds.), Behind the Mind: Methods, Models and Results in Translation Process Research (pp. 12-38). Samfundslitteratur Press. https://doi.org/10.1075/btl.45

Hamouda, A. (2013). A Study of Dictionary Use by Saudi EFL Students at Qassim University. Studies in English Language Teaching, 1(1), 227. https://doi.org/10.22158/selt.v1n1p227

Kodura, M. (2016). Dictionary-using skills of translation students. The Central European Journal of Social Sciences and Humanities, 4, 235-242.

Koyama, T. (2015). The impact of E-dictionary strategy training on EFL class. Lexicography, 2(1), 35-44. https://doi.org/10.1007/s40607-015-0018-3

L'homme, M. C., \& Cormier, M. C. (2014). Dictionaries and the digital revolution: A focus on users and lexical databases. International Journal of Lexicography, 27(4), 331-340. https://doi.org/10.1093/ijl/ecu023

Law, W. (2009). Translation Students' Use of Dictionaries: A Hong Kong Case Study for Chinese to English Translation. University of Durham.

Levy, M., \& Steel, C. (2014). Language learner perspectives on the functionality and use of electronic language dictionaries. ReCALL, 27(2), 177-196. https://doi.org/10.1017/S095834401400038X

Lew, R. (2013a). From paper to electronic dictionaries: Evolving dictionary skills. Lexicography and Dictionaries in the Information Age. Selected Papers from the 8th ASIALEX International Conference, 1, 79-84. Retrieved from http://www.asialex2013.org/03_Asialex8_Proceedings_Internet_Papers 1-25.pdf

Lew, R. (2013b). Online dictionary skills. In Electronic lexicography in the 21st century: Thinking outside the paper (Issue May, pp. 16-31). Proceedings of the eLex 2013 conference, 17-19 October 2013, Tallinn, Estonia. Retrieved from http://eki.ee/elex2013/proceedings/eLex2013_02_Lew.pdf

Lew, R., \& De Schryver, G. M. (2014). Dictionary users in the digital revolution. International Journal of Lexicography, 27(4), 341-359. https://doi.org/10.1093/ijl/ecu011

Lew, R., \& Szarowska, A. (2017). Evaluating online bilingual dictionaries: The case of popular free English-Polish dictionaries. ReCALL, 29(2), 138-159. https://doi.org/10.1017/S0958344016000252

Liang, P., \& Xu, D. (2018). An empirical study of EFL learners' dictionary use in Chinese-English translation. Lexikos, 28, 221-244. https://doi.org/10.5788/28-1-1463

Mavrommatidou, S. (2018). Exploring the frequency and the type of users' digital skills using S.I.E.D.U. (pp. 909-914). Stavroula, EURALEX Proceedings.

Nesi, H. (2000). Electronic dictionaries in second language vocabulary comprehension and acquisition: The state of the art. In E. L. C. R. U. Heid \& S. Evert (Eds.), Proceedings of the 9th EURALEX International Congress (pp. 839-848). Institut für Maschinelle Sprachverarbeitung.

Nesi, H. (2013). Researching Users and Uses of Dictionaries. In H. Jackson (Ed.), The Bloomsbury Companion to Lexicography (pp. 62-74). Bloomsbury. https://doi.org/10.5040/9781472541871.ch-005

Nesi, H. (2014). Dictionary use by English language learners. Language Teaching, 47(1), 38-55. https://doi.org/10.1017/S0261444813000402

PACTE. (2003). Building a translation competence model. In F. Alves (Ed.), Triangulating translation: perspectives in process-oriented research (pp. 43-66). John Benjamins. https://doi.org/10.1075/btl.45.06pac

PACTE Group. (2005). Investigating translation competence: Conceptual and methodological issues. Meta, 50(2), 609-619. https://doi.org/10.7202/011004ar

Roberts, R. P. (1992). Translation pedagogy: Strategies for improving dictionary use. TTR: Traduction, Terminologie, Rédaction, 5(1), 49-76. https://doi.org/10.7202/037106ar

Sabbah, N., \& Alsalem, R. (2018). Female translation students' knowledge and use of online dictionaries and 
terminology data banks: A case study. Arab World English Journal for Translation and Literary Studies, 2(2), 81-102. https://doi.org/10.24093/awejtls/vol2no2.6

Tulgar, A. (2017). Dictionary Use of Undergraduate Students in Foreign Language Departments in Turkey at Present. Universal Journal of Educational Research, 5(12B), 51-57. https://doi.org/10.13189/ujer.2017.051406

Wolter, L. (2015). Dictionary Use and Preferences of L2 English Learners in an Intensive English Context. St. Cloud State University, USA.

\section{Copyrights}

Copyright for this article is retained by the author, with first publication rights granted to the journal.

This is an open-access article distributed under the terms and conditions of the Creative Commons Attribution license (http://creativecommons.org/licenses/by/4.0/). 